\title{
AS AVALIAÇÕES EXTERNAS E O ENSINO DE GEOGRAFIA NA REDE ESTADUAL DE EDUCAÇÃO DO RIO DE JANEIRO ${ }^{1}$
}

\section{External evaluations and geography teaching in Rio de Janeiro State education system}

\author{
Suzana Campos Silva \\ Professora da Educação Básica nas redes estadual e municipal \\ suzanarb2003@yahoo.com.br
}

Artigo recebido em 16/09/2016 e aceito para publicação em 26/06/2017

DOI: $10.12957 /$ tamoios.2017.25610

\section{Resumo}

O objetivo deste trabalho é analisar o ensino de Geografia que vem sendo efetivado nas escolas estaduais do Rio de Janeiro, no contexto das políticas públicas educacionais, com destaque para as avaliações externas. Para essa análise foram considerados o modelo de gestão educacional vigente na rede estadual de ensino entre os anos de 2007 e 2014; as avaliações do Saerj e do Saerjinho e a construção de índices para a educação. Através de algumas questões presentes nas provas de Geografia nos anos de 2013 e 2014 foram avaliadas a forma como os temas da disciplina são abordados e o papel dessas provas para o ensino como um todo.

Palavras-chave: Ensino de Geografia; Políticas Públicas Educacionais; Avaliações Externas.

\begin{abstract}
The objective of this study is to analyze the teaching of geography that has been effected in the state schools of Rio de Janeiro, in the context of educational policies, especially external evaluations. For this analysis were considered the model of the current state educational management between the years 2007 and 2014, evaluations of Saerj and Saerjinho and the construction of indices for education. Through some questions present in the Geography tests in the years of 2013 and 2014 will be evaluated the way the subjects of the discipline are approached and the role of these tests for the teaching as a whole.
\end{abstract}

Keywords: Geography Teaching; Educational Public Policy; External evaluation. 


\section{INTRODUÇÃO}

A Geografia, ciência que analisa múltiplos fenômenos espaciais se faz presente no cotidiano e por isso atinge cada indivíduo antes mesmo da noção do que é uma disciplina escolar ou um campo de estudo científico. Mas, a partir do momento em que essa se insere no contexto escolar é necessário que permita que a partir dela os alunos tenham a possibilidade de construir uma visão mais clara do mundo ao seu redor.

A forma como essa disciplina tem sido ensinada nas escolas estaduais do Rio de Janeiro foi fortemente impactada pelas políticas públicas educacionais implementadas nos últimos anos. Essas políticas se tornaram centrais, sobretudo a partir do momento em que a educação brasileira passou por muitas reformas e essas trouxeram para as escolas os filhos da classe trabalhadora, para quem as vagas antes eram restritas. Mas, essa inserção se deu de forma precária.

Por considerar fundamental a compreensão deste processo de universalização do ensino básico é importante que sejam avaliadas as políticas públicas educacionais e seus efeitos diretos no ambiente escolar, onde é possível observar a realidade atrás das estatísticas apresentadas pelos governos. Para isso, foi definido como objeto de análise o ensino de Geografia que vem sendo efetivado nas escolas estaduais do Rio de Janeiro, no contexto das políticas públicas educacionais, com destaque para as avaliações externas.

\section{O CONTEXTO DAS AVALIAÇÕES EXTERNAS APLICADAS NA REDE ESTADUAL DE ENSINO DO RIO DE JANEIRO}

Dentro do conjunto de medidas que fizeram parte das políticas públicas educacionais brasileiras nas últimas duas décadas destacam-se as avaliações externas. Essas avaliações têm sido os principais instrumentos utilizados pelos governos tanto em escala nacional quanto em estados e municípios para mensuração da "qualidade" do ensino que promovem.

Tais avaliações chegaram ao Brasil, de fato, em 1990, ano da primeira aplicação do Sistema de Avaliação da Educação Básica (Saeb). Não por mera coincidência, um ano após o Consenso de Washington que trouxe para o país uma série de medidas neoliberais com o intuito de promover o desenvolvimento econômico, incluindo para isso o setor educacional, que a partir de então teria financiamento e outros auxílios para alcançar as metas estabelecidas pelas entidades financiadoras internacionais.

O discurso do governo brasileiro passou a ser em prol da melhoria da qualidade e universalização do acesso à escola, oferecendo subsídios concretos para a formulação, reformulação e o monitoramento das políticas públicas voltadas para a Educação Básica.

A criação de sistemas para a avaliação da Educação Básica foi um dos grandes passos para adequar o Brasil às necessidades econômicas nas quais se inseriu, permitindo a criação de um mercado de trabalho mais qualificado.

Para atender as demandas criadas pelas instituições financeiras internacionais que passaram a atuar de forma decisiva nas políticas educacionais brasileiras, foram criadas para a Educação Básica e também para o Ensino Superior sistemas de avaliação com a intenção de mensurar a qualidade do ensino.

Para a Educação Básica foram criados o Saeb que fornece os dados para a construção do Índice de Desenvolvimento da Educação Básica (Ideb), o Exame Nacional do Ensino Médio (Enem) e a Provinha Brasil. O Ensino Superior passou a ser avaliado pelo Sistema Nacional de Avaliação da Educação Superior (Sinaes) por meio, 
dentre outros instrumentos, do Exame Nacional de Desempenho dos Estudantes (Enade) (SILVA, 2010, p. 430).

Essas políticas em âmbito nacional começaram a repercutir nos estados e municípios, que passaram a ter seus sistemas de ensino classificados pelos índices produzidos pelas avaliações externas. No Estado do Rio de Janeiro, a partir dos anos 2000, uma série de políticas foram criadas para deixar o estado em boa situação no cenário nacional. As principais mudanças ocorreram a partir de 2007 com a eleição do governador Sérgio Cabral Filho (Partido do Movimento Democrático Brasileiro PMDB), que esteve no cargo por dois mandatos consecutivos até 03 de abril de 2014, quando renunciou ao cargo deixando em seu lugar o então vice-governador Luiz Fernando Pezão, também do PMDB.

Ao longo dos anos de governo de Sérgio Cabral, os projetos para a educação do estado do Rio de Janeiro estiveram pautados na mensuração da qualidade do ensino, através de índices e avaliações externas, assim como da constante avaliação do trabalho docente.

Para caracterizar as intenções do governo, neste período sucederam-se três diferentes secretários de educação. O primeiro deles foi Nelson Maculan Filho, engenheiro e professor, que esteve no cargo de janeiro de 2007 até fevereiro de 2008. De fevereiro de 2008 a outubro de 2010, assumiu a analista de sistemas e gestora, Tereza Cristina Porto Xavier. A partir de seis de outubro de 2010, a terceira pessoa no cargo passou a ser o economista e financista Wilson Risolia Rodrigues (ARAUJO, 2012, p. 53), que esteve na função até dezembro de 2014.

Essas mudanças na direção da Secretaria de Estado de Educação do Rio de Janeiro (SEEDUC) deixaram claro que o objetivo era construir uma secretaria com características empresariais, pautada em resultados e bom uso dos recursos financeiros.

Com o intuito de alavancar o ensino do estado do Rio de Janeiro no cenário nacional, que nos primeiros anos do Ideb (2005, 2007 e 2009) esteve em posições ruins, sobretudo em 2009, quando ocupou a $26^{a}$ posição entre os estados brasileiros, nos dados referentes ao Ensino Médio, que é o nível de ensino sob responsabilidade da rede estadual, o governo estadual do Rio de Janeiro criou duas avaliações próprias: o Sistema de Avaliação do Estado do Rio de Janeiro (Saerj) e o Saerjinho. Essas avaliações estiveram em vigor até o final de 2015, pois em 2016, com o movimento de greve dos professores e a ocupação de muitas escolas pelos estudantes, a SEEDUC decidiu suspender a aplicação das provas.

O Saerj, criado em 2008, seguindo o modelo da Prova Brasil aplicada para construção do Ideb, tinha como objetivo avaliar o desempenho em Língua Portuguesa e em Matemática de alunos do $5^{\circ}$ e $9^{\circ}$ anos do Ensino Fundamental e do $3^{\circ}$ ano do Ensino Médio, e em outras modalidades de ensino com anos equivalentes a esses (RIO DE JANEIRO, 2011a).

O Centro de Políticas Públicas e Avaliação da Educação (Caed), da Universidade Federal de Juiz de Fora, era a instituição que operacionalizava o Saerj, assim como outros programas estaduais e municipais destinados a mensurar $o$ rendimento de estudantes de escolas públicas.

Para a realização do Saerj os alunos eram motivados através de premiações concedidas aos primeiros colocados, para os quais eram distribuídos computadores e tablets. Os profissionais das escolas com melhores resultados também eram bonificados ao final de cada ano com valores acrescidos a seus salários.

Como forma de aprimorar ainda mais o Saerj, no ano de 2011, o Saerjinho começou a ser aplicado a partir de abril. Segundo a SEEDUC, essa avaliação diagnóstica bimestral passou a servir como sistema de avaliação do processo de ensino e 
aprendizagem nas escolas (RIO DE JANEIRO, 2011b). Inicialmente, como um "ensaio" para o Saerj, eram realizadas apenas provas de Matemática e Língua Portuguesa.

Em 2012 foram incluídas questões de Ciências Físicas e Biológicas, em 2013 foi incluída a disciplina de Geografia e em 2014 os conteúdos de História, tanto para as turmas do Ensino Fundamental $\left(5^{\circ}\right.$ e $9^{\circ}$ anos) quanto para as do Ensino Médio $\left(1^{\circ}, 2^{\circ} \mathrm{e}\right.$ $3^{\circ}$ anos). Estas novas disciplinas foram alocadas em dois grandes grupos, a exemplo do que é feito no Enem. São eles: Ciências Humanas (Geografia e História) e Ciências da Natureza (que no Ensino Fundamental compreende a disciplina de Ciências e no Ensino Médio Química, Física e Biologia).

A princípio realizavam a prova alunos do $5^{\circ}$ e $9^{\circ}$ anos do Ensino Fundamental e dos três anos do Ensino Médio. Mas, assim como nos conteúdos, também aqui foram realizadas mudanças.

Em 2015 as turmas e disciplinas avaliadas pelo Saerjinho eram:

$\checkmark 5^{\circ}, 6^{\circ}$ e $9^{\circ}$ anos do Ensino Fundamental: Língua Portuguesa, Matemática, Ciências Humanas e Ciências da Natureza.

$\checkmark 1^{\circ}, 2^{\circ}$ e $3^{\circ}$ anos do Ensino Médio Regular, Integrado, Inovador, Intercultural e Experimental: Língua Portuguesa, Matemática, Ciências Humanas e Ciências da Natureza.

$\checkmark$ Redação - era aplicada somente no $1^{\circ}$ bimestre para as turmas de $3^{\circ}$ ano do Ensino Médio e do Curso Normal.

$\checkmark$ Etapas equivalentes da EJA, Projeto Autonomia, Programa de Correção de Fluxo e Curso Normal: Língua Portuguesa e Matemática (CAED, 2015).

No que se refere à aplicação das avaliações, para o Saerj era feita a seleção de profissionais das escolas estaduais que recebiam treinamento para a aplicação do exame e eram remunerados para isso. Já para as provas do Saerjinho era solicitado que os próprios professores das turmas em horário de aula aplicassem as avaliações. O que sempre gerava descontentamento no corpo docente que possuía grande número de profissionais contrários a realização dessas avaliações externas.

Para a SEEDUC através de um "treinamento" bimestral seria mais fácil os alunos se adaptarem a esses tipos de provas e os professores deveriam adaptar-se também a aplicar seus conteúdos direcionando-os para as avaliações. Por isso, também foi criado o Currículo Mínimo e uma Matriz de Referência específica para cada disciplina do Saerjinho, como uma forma de ação conjunta, agregando avaliações e conteúdos.

Em 2011, as Matrizes de Referência para Avaliação Diagnóstica do Saerjinho foram elaboradas com base nos seguintes documentos: as matrizes do Saerj, cujas habilidades encontram correspondência direta com as matrizes do Saeb e da Prova Brasil; o Currículo Mínimo e as Diretrizes Curriculares dos anos iniciais do Ensino Fundamental da SEEDUC-RJ, os quais foram analisados detalhadamente, visando ao levantamento das habilidades consideradas fundamentais para cada período de escolarização - e bimestre avaliado (Fonte: <http://www.saerjinho.caedufjf.net>. Acesso em: 01 de ago. 2015)

Essas matrizes foram revistas em 2012 porque ocorreram mudanças também no Currículo Mínimo e a inserção dos conteúdos de Ciências da Natureza na prova do Saerjinho. Em 2013 foram elaboradas matrizes para a disciplina de Geografia e em 2014 para a de História.

Segundo a Secretaria de Estado de Educação, para a elaboração das matrizes dessas áreas, considerou-se apenas os documentos disponíveis para a rede estadual - o 
Currículo Mínimo e as Diretrizes Curriculares dos anos iniciais do Ensino Fundamental -, pois o Saeb e a Prova Brasil não avaliam estas áreas do conhecimento.

Outro ponto importante citado pela SEEDUC é que a montagem dos testes do Saerjinho obedece aos descritores apresentados em cada matriz, de acordo com o ano de escolaridade e o bimestre avaliado. No primeiro bimestre, além das habilidades específicas que estão diretamente relacionadas ao Currículo Mínimo, a matriz contempla ainda habilidades de etapas de escolarização anteriores.

Sendo assim, além do Currículo Mínimo o professor deveria fazer uso da Matriz de Referência para melhor preparar os seus alunos para as avaliações do Saerjinho, já que, ao menos no primeiro bimestre, havia divergência entre os conteúdos indicados. Mas, muitas vezes os professores não tinham clareza dessa informação e ficavam sem saber em qual documento deveriam se pautar e por isso escolhiam apenas um deles, sendo que a Matriz de Referência só contemplava os conteúdos do $1^{\circ}$ ao $3^{\circ}$ bimestre quando eram aplicadas as provas do Saerjinho.

Para estimular e/ou obrigar professores e alunos a participarem deste sistema de avaliação foram criadas certas medidas. Para os professores além de aplicação dos conteúdos do Currículo Mínimo adequado ao bimestre, também foi solicitado que fossem atribuídas notas às avaliações do Saerjinho, que deveriam ter dois gabaritos preenchidos pelos alunos. Um desses ficava na escola para ser corrigido pelo professor, que depois deveria revisar as provas com os alunos. O outro deveria ser enviado ao Caed para correção eletrônica e confecção de dados para a SEEDUC classificar, advertir ou premiar as escolas. Aos alunos tornou-se obrigatória a confecção das provas à medida em que eram atribuídos pontos que faziam parte da média bimestral de cada uma das disciplinas avaliadas. Também eram sorteados brindes ofertados pela própria escola para os melhores colocados em cada ano de escolaridade, em uma versão menor do que era feito pela secretaria de educação com o Saerj. Ou seja, eram mantidos os padrões de competitividade e quantificação para estimular os "bons resultados".

Os conteúdos de Geografia, História e Ciências da Natureza não interessam diretamente aos bons resultados esperados para o Ideb, mas fazer com que os alunos lidassem o tempo todo com o modelo das avaliações externas os condicionava a melhorarem para tais avaliações, o que também é feito com o objetivo de melhores resultados nas provas do Enem, que contempla conteúdos além de Língua Portuguesa e Matemática. Embora, a classificação no Enem não tenha um peso tão grande quanto o Ideb para a rede estadual de ensino, esse exame também serve para mensurar a qualidade do Ensino Médio da rede.

O quantitativo de questões abordadas em cada disciplina nas avaliações do Saerjinho variava de um ano para o outro, sendo atribuído menor número de questões as disciplinas consideras menos importantes, neste caso Geografia e História, e mais questões as disciplinas de Língua Portuguesa, Matemática (que são parâmetros para todas as avaliações externas) e de Ciências da Natureza.

A tabela 1 mostra a quantidade de questões em cada ano de escolaridade em que os alunos realizavam a prova do Saerjinho. 
Tabela 1 - Distribuição de questões do Saerjinho por disciplinas e anos.

\begin{tabular}{|c|c|c|c|c|c|c|}
\hline Disciplinas/Anos & $\mathbf{5}^{\mathbf{0}}$ & $\mathbf{6}^{\mathbf{0}}$ & $\mathbf{9}^{\mathbf{0}}$ & $\mathbf{1}^{\mathbf{0}}$ & $\mathbf{2}^{\mathbf{0}}$ & $\mathbf{3}^{\mathbf{0}}$ \\
\hline $\begin{array}{c}\text { Língua } \\
\text { Portuguesa }\end{array}$ & 22 & 22 & 26 & 26 & 26 & 26 \\
\hline Matemática & 22 & 22 & 26 & 26 & 26 & 26 \\
\hline $\begin{array}{c}\text { Ciências da } \\
\text { Natureza }\end{array}$ & 21 & 21 & 27 & 27 & 27 & 27 \\
\hline História & 07 & 07 & 09 & 09 & 09 & 09 \\
\hline Geografia & 07 & 07 & 09 & 09 & 09 & 09 \\
\hline Total & 79 & 79 & 97 & 97 & 97 & 97 \\
\hline
\end{tabular}

Dados tabelados pela autora a partir de informações da página eletrônica do Caed.

Fonte: <http://www.saerjinho.caedufjf.net/diagnostica/inicio.faces>. Acesso em: 01 ago. 2015.

Nessa tabela é importante observar que enquanto os demais conteúdos incluíam mais de vinte questões em todos os anos de escolaridade, Geografia e História variam de sete para nove apenas. Mesmo considerando que no Ensino Médio os conteúdos de Ciências da Natureza agregam três disciplinas (Biologia, Química e Física) percebe-se que essa grande área tem um peso maior que Ciências Humanas.

O "treinamento" para as avaliações externas trouxe resultados quantitativos, já que o objetivo de alcançar melhores posições no Ideb foi alcançado. O estado do Rio de Janeiro passou a ocupar a $4^{a}$ posição em 2013. Mas, se for feita uma observação isolada dos resultados do Saerjinho, em todas as disciplinas há evidências do fracasso dessas avaliações. A tabela 2 exemplifica os resultados nas avaliações de Geografia nos anos de 2013 e 2014.

Tabela 2 - Geografia - Ensino Regular

\begin{tabular}{|c|c|c|}
\hline Etapa de Escolaridade & $\begin{array}{c}\text { \% Total de Acertos } \\
\mathbf{2 0 1 3}\end{array}$ & $\begin{array}{c}\text { \% Total de Acertos } \\
\mathbf{2 0 1 4}\end{array}$ \\
\hline 5 ANO & 63,0 & 69,3 \\
\hline 9o ANO & 63,2 & 57,6 \\
\hline 1a SÉRIE EM & 48,9 & 40,0 \\
\hline 2a SÉRIE EM & 39,3 & 32,1 \\
\hline 3a SÉRIE EM & 58,1 & 47,1 \\
\hline
\end{tabular}

Fonte: <http://www.saerjinho.caedufjf.net/diagnostica/inicio.faces>. Acesso em: 01 ago. 2015.

A tabela mostra uma média anual considerando os três bimestres de realização das provas. Em uma primeira observação desses dados é possível notar que houve uma queda no percentual de acertos, com exceção do $5^{\circ}$ ano de escolaridade. Outra característica desses dados é que os percentuais de acertos eram maiores nos anos do Ensino Fundamental do que nos do Ensino Médio. A diminuição no número de acertos pode estar relacionada ao maior número de alunos conscientizados por professores de que esse tipo de avaliação não mede os conhecimentos como deveria e que por isso optavam por não realizar as provas; também pode significar uma redução no nível de conhecimento dos alunos, ainda que as avaliações utilizassem baixo grau de complexidade para alcançar melhores resultados, como será visto mais adiante. 
Esses resultados apontam para o fato de que mesmo com um maciço investimento da SEEDUC na aplicação de avaliações externas houve uma queda no rendimento dos alunos. A associação direta da "qualidade" do ensino com resultados de provas não tem alcançado as metas esperadas e por isso há grande preocupação com outros aspectos que garantem a construção de índices favoráveis como o fluxo (aprovação/reprovação) e a evasão.

Mesmo diante desses dados negativos, muitos municípios do estado do Rio de Janeiro entraram em acordo com o governo estadual para também aplicarem as provas do Saerjinho e Saerj. Segundo dados divulgados pela SEEDUC, em 2014, um grupo de 74 dos 92 municípios fluminenses decidiu utilizar as avaliações que eram aplicadas para as turmas do $5^{\circ}$ e $9^{\circ}$ anos do Ensino Fundamental, com conteúdos apenas de Matemática e Língua Portuguesa, porque o maior objetivo desses municípios é preparar seus alunos para a confecção da Prova Brasil que compõe o Ideb.

O projeto da SEEDUC era voltado para a adequação de todo sistema público de ensino do estado do Rio de Janeiro para a elaboração de avaliações externas, já que grande parte dos alunos que estão nas redes municipais de ensino cursarão o Ensino Médio em escolas da rede estadual, pois os municípios, com pouquíssimas exceções, só oferecem o Ensino Fundamental. Por esses motivos a Secretaria de Estado de Educação ofertava gratuitamente as avaliações para as redes municipais.

Para auxiliar na interpretação dos resultados das avaliações do Saerj e do Saerjinho foram criados índices próprios para cada uma delas, o Iderj (Índice de Desenvolvimento da Educação do Estado do Rio de Janeiro) e o Iderjinho.

Em 2011, dentro do Plano de Metas estabelecido pelo Programa de Educação do Estado, foi criado o Iderj, que era produto de dois indicadores: Indicador de Desempenho (ID) e Indicador de Fluxo (IF). Muito similar ao Ideb, o Iderj traduzia duas realidades, fluxo e desempenho, em um número de 0,0 (zero) a 10,0 (dez).

A criação do Iderj que estabelecia as metas anuais que deveriam ser alcançadas foi acompanhada da criação do Iderjinho, que estabelecia metas bimestrais. Ambos tinham como objetivo contribuir para o Ideb que faz verificações bienais. Para ilustrar esta relação entre os índices a SEEDUC criou o esquema exposto na figura 1.

Figura 1 - Indicadores de desempenho educacional.

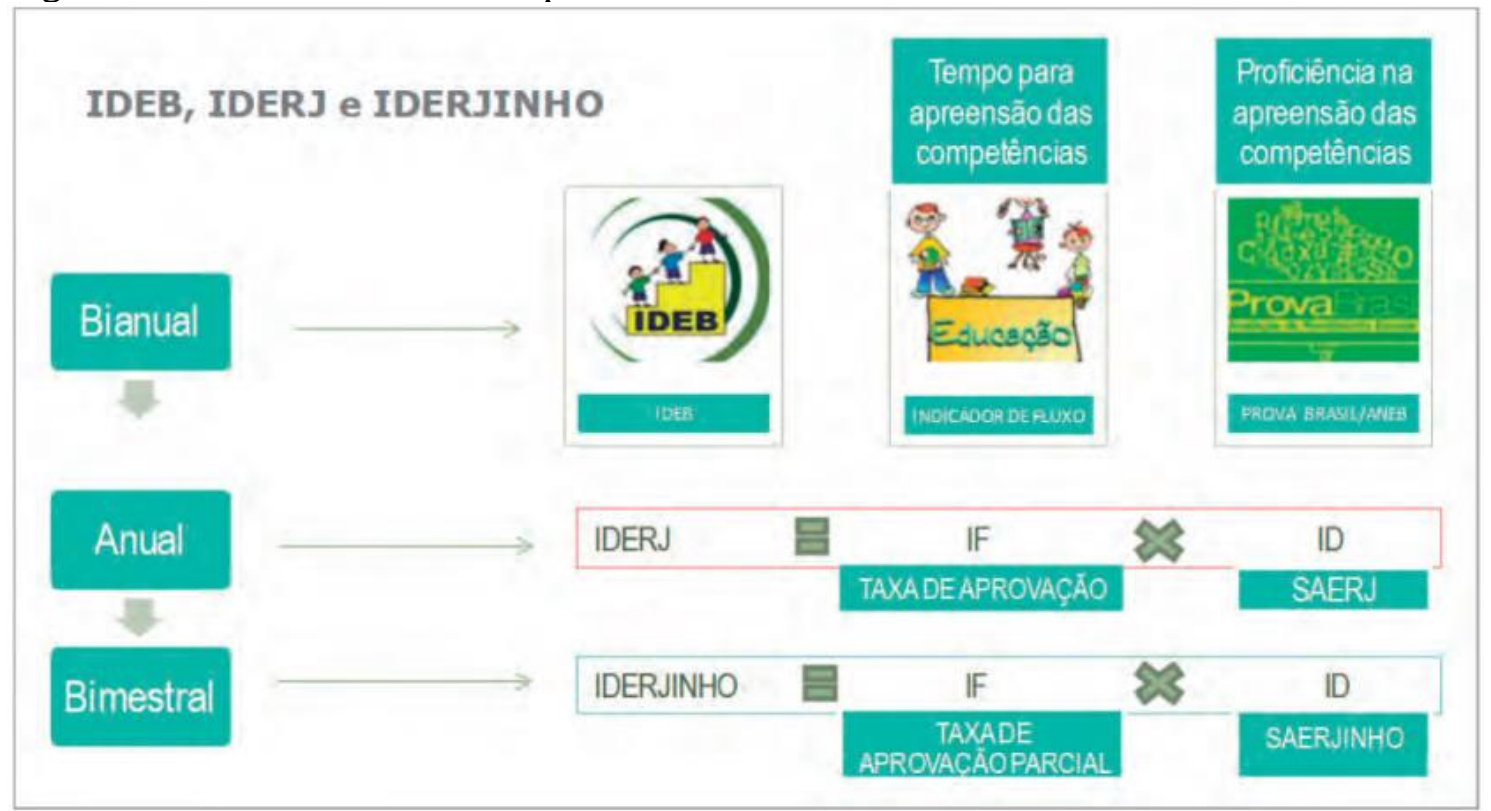

Relatório de Gestão e Políticas Públicas - Educação 2014, p. 28.

Fonte: <http://www.rj.gov.br/web/seeduc/exibeconteudo?article-id=711577>. Acesso em: 10 maio 2015. 
Segundo a SEEDUC a vantagem do Iderjinho era que esse fornecia dados bimestrais, apontando para as possíveis falhas do sistema de ensino que poderiam ser corrigidos até a confecção do Iderj, que fornecia dados anuais a respeito da "qualidade" da educação no estado. Com os resultados do Iderj era possível desenvolver ações pedagógicas para que nos momentos de avaliações do Ideb os problemas já tivessem sido superados e o estado do Rio de Janeiro obtivesse os melhores resultados possíveis. Dentre as ações feitas pela SEEDUC para melhoria desses índices estavam: programas para formação de professores; frequentes reuniões pedagógicas para discussão e responsabilização dos resultados; reforço escolar destinado as disciplinas de Matemática e Língua Portuguesa.

A partir da análise das obras de Gaudêncio Frigotto (2010) e István Mészáros (2008) é possível perceber que a criação desse sistema composto por avaliações externas e índices é mais um instrumento do capitalismo para fazer da escola um local útil para a "criação" de trabalhadores adequados aos novos postos de trabalho. O trabalhador de hoje tem que ser capaz de dominar as mais modernas tecnologias, assim como de oferecer respostas rápidas diante dos desafios impostos pela função que exerce. Portanto, o aluno deve ser capaz de expor em avaliações tudo o que aprendeu ou que espera-se que tenha aprendido. Caso isso não funcione há algum problema que precisa ser corrigido e cabe a escola resolver antes que esse aluno, futuro trabalhador, chegue a empresa capitalista.

Essas ideias estão postas por István Mészáros (2008, p. 15) quando afirma que:

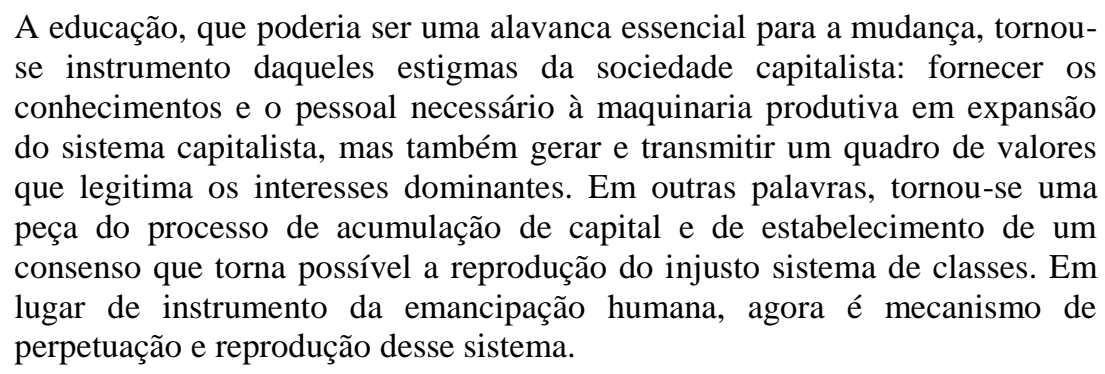

A escola planejada no contexto da rede estadual do Rio de Janeiro tornou-se mais um instrumento para manutenção dos interesses da sociedade capitalista. Projeto esse que manifesta-se desde a escala nacional pela ação e controle promovidos pelo Banco Mundial sobre as políticas educacionais para todo o Brasil.

Para Gaudêncio Frigotto (2010) este é o viés improdutivo da escola, que serve para manter a própria produtividade do sistema capitalista, ao manter o domínio das classes dominantes e a desqualificação do conhecimento. A escola de hoje ajusta-se muito mais às necessidades de quantificação para obter bons resultados em avaliações externas do que para promover um ensino capaz de formar cidadãos conscientes de seu papel no mundo.

É importante salientar que o questionamento não direciona-se ao ato de avaliar, mas sim a forma como as avaliações têm sido inseridas no contexto escolar. Não se deve negar o papel e a importância da avaliação.

As implicações deste tipo de projeto educacional para o ensino serão discutidas a seguir, com foco na disciplina de Geografia.

\section{O SAERJINHO E O ENSINO DE GEOGRAFIA}

Os modelos "ideais" de gestão educacional, como o que tem sido construído na rede estadual do Rio de Janeiro, há muito já vêm sendo questionados por vários 
pensadores no campo da educação, sobretudo no que diz respeito à construção de índices pautados em avaliações externas.

Para Philippe Perrenoud (2003), por exemplo, no que se refere à avaliação, a escola só pode avaliar, no cotidiano, aquilo que ela ensinou, enquanto que as avaliações externas em larga escala medem o nível de domínio daquilo que se imagina ter sido ensinado em todas as escolas a partir do currículo formal. Para o autor tais avaliações não levam em conta a realidade diversificada do ensino e do trabalho escolar.

Nas avaliações diagnósticas bimestrais do Saerjinho como e o que deveria ser avaliado era decidido fora da escola, sem participação efetiva dos professores que lidavam cotidianamente com as necessidades e interesses de cada aluno. Embora a SEEDUC classificasse essas avaliações como diagnósticas distinguindo-as do que seriam as avaliações externas - Saerj e Prova Brasil - a preparação também era feita fora da escola, havendo distinção apenas no modo de aplicação, que era realizada pelos próprios professores das unidades escolares sob orientação da equipe diretiva.

Para exemplificar a forma como eram construídas as avaliações de Geografia estão expostas a seguir questões das provas do $9^{\circ}$ ano do Ensino Fundamental, $1^{\circ}, 2^{\circ}$ e $3^{\circ}$ anos do Ensino Médio aplicadas nos anos de 2013 (ano de inserção dos conteúdos da disciplina) e 2014. Essa escolha foi feita em função dessas questões permitirem a análise de distintos níveis de ensino e por esses anos de escolaridade estarem presentes em um número maior de escolas.

Ao observar esses exemplos é fundamental frisar que "a avaliação é um suporte importante para o processo de ensino-aprendizagem, permitindo a análise da ação educativa num processo contínuo, dando subsídios ao redimensionamento da prática pedagógica" (COPATTI, 2014, p. 168). Nessa situação a preocupação está no que o aluno aprendeu e não na mensuração de resultados, como ocorre com as avaliações externas, constituídas apenas por questões de múltipla escolha, nas quais muitas vezes os alunos confessam não terem lido os enunciados, tendo "chutado" qualquer opção para resposta.

A primeira questão selecionada foi aplicada no $2^{\circ}$ bimestre de 2013 para as turmas de $9^{\circ}$ ano (figura 2). Na questão há um mapa que localiza a concentração da produção de castanhas de caju em uma região do Brasil e pergunta-se que região é essa. Embora os alunos desse ano de escolaridade devam reconhecer bem o mapa do Brasil, é extremamente incoerente que esse tema apareça em um bimestre que tem como foco, tanto da Matriz de Referência quanto do Currículo Mínimo, o continente europeu. É importante citar que nesse caso ambos os documentos versam sobre os mesmos temas, porque, em especial no $9^{\circ}$ ano, há divergências entre as habilidades indicadas nos dois documentos. 
Figura 2 - Questão 38 da prova de Geografia do $2^{\circ}$ bimestre de 2013 - $9^{\circ}$ ano

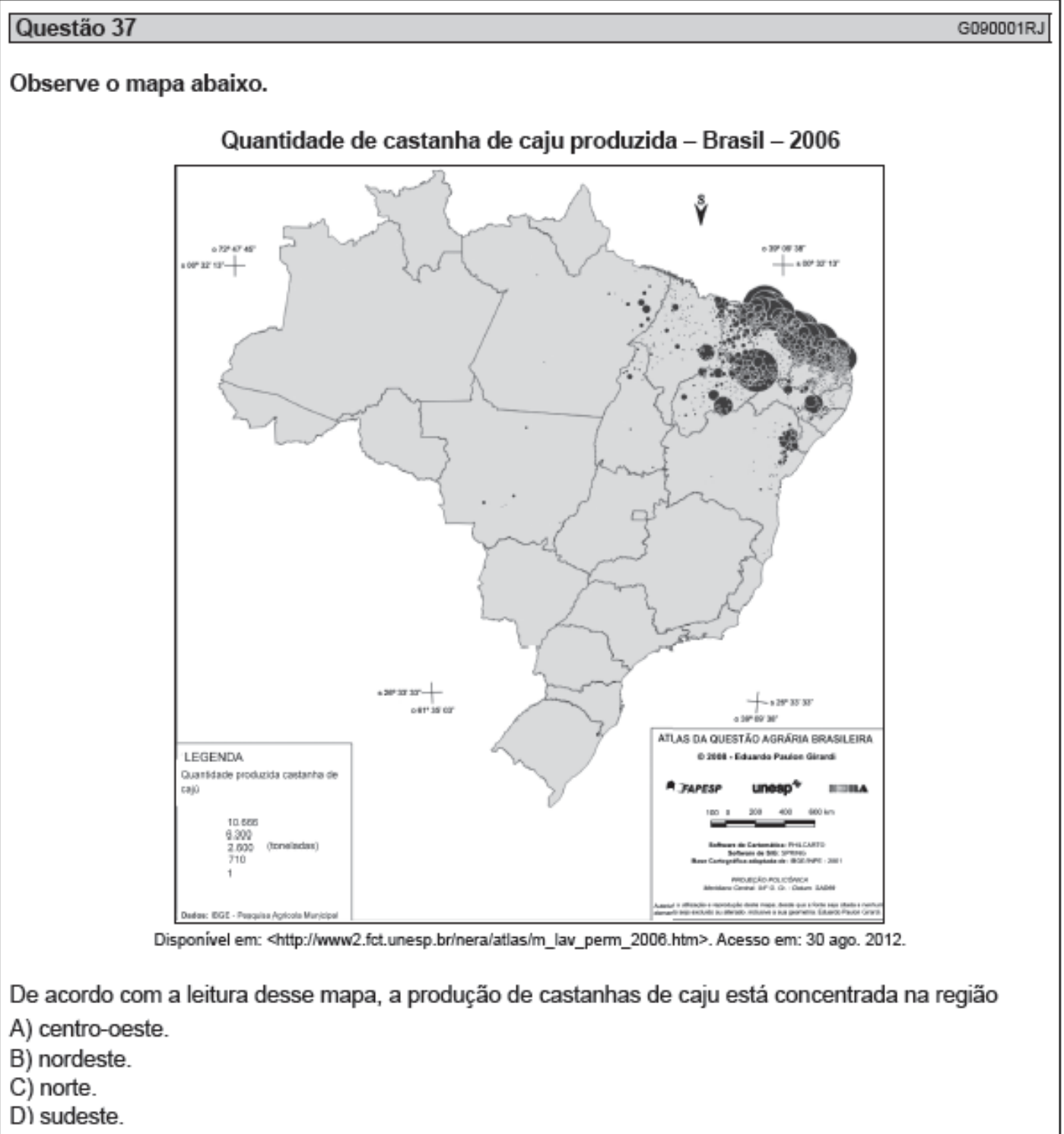

Fonte: <http://www.saerjinho.caedufjf.net/diagnostica/inicio.faces>. Acesso em: 01 ago. 2015.

Segundo Carina Copatti (2014, p. 170) "na Geografia Escolar, o ato de avaliar pressupõe a utilização de instrumentos que ampliem a capacidade de leitura e compreensão de diferentes fenômenos sociais ocorridos no espaço geográfico". Considerando essa afirmação é possível inferir que a questão apresentada acima não permite aos alunos a ampliação da capacidade de compreensão desses diferentes fenômenos, já que os limita ao entendimento superficial, apenas com foco na localização, independente de outras relações socioespaciais. Caberia nesse caso ao professor criar novas possibilidades de análise, o que também estaria acompanhado de outros instrumentos que permitiriam uma maior compreensão dos fenômenos. Mas, como o professor não tinha acesso a essas provas antes de serem aplicadas e não podia intervir no modo como as questões eram formuladas não havia possibilidade de fazer desse momento de avaliação também um momento de construção do conhecimento. Assim, a avaliação que poderia ser "considerada um suporte para o processo de ensinoaprendizagem, permitindo a análise da ação educativa num processo contínuo, investigando e dando subsídios ao redimensionamento da prática pedagógica" (COPATTI, 2014, p. 170) não atingiu seu objetivo. 
Nos três anos do Ensino Médio a distorção entre as habilidades do Currículo Mínimo e da Matriz de Referência tornam-se menores, mas, problemas como a falta de contextualização e desenvolvimento de argumentação crítica mantêm-se.

No $1^{\circ}$ ano, em meio a questões que em muito assemelhavam-se a questão apresentada para o $9^{\circ}$ ano (figura 2), a prova do $2^{\circ}$ bimestre de 2014 trouxe a questão 43 que tratava de biomas (figura 3). Na questão foi feita apenas uma descrição do bioma deserto ilustrada com imagens, o que dificilmente levaria o aluno a errar, porque toda a descrição está muito presente no senso comum.

Figura 3 - Questão 43 da prova de Geografia do $2^{\circ}$ bimestre de 2014 - $1^{\circ}$ ano

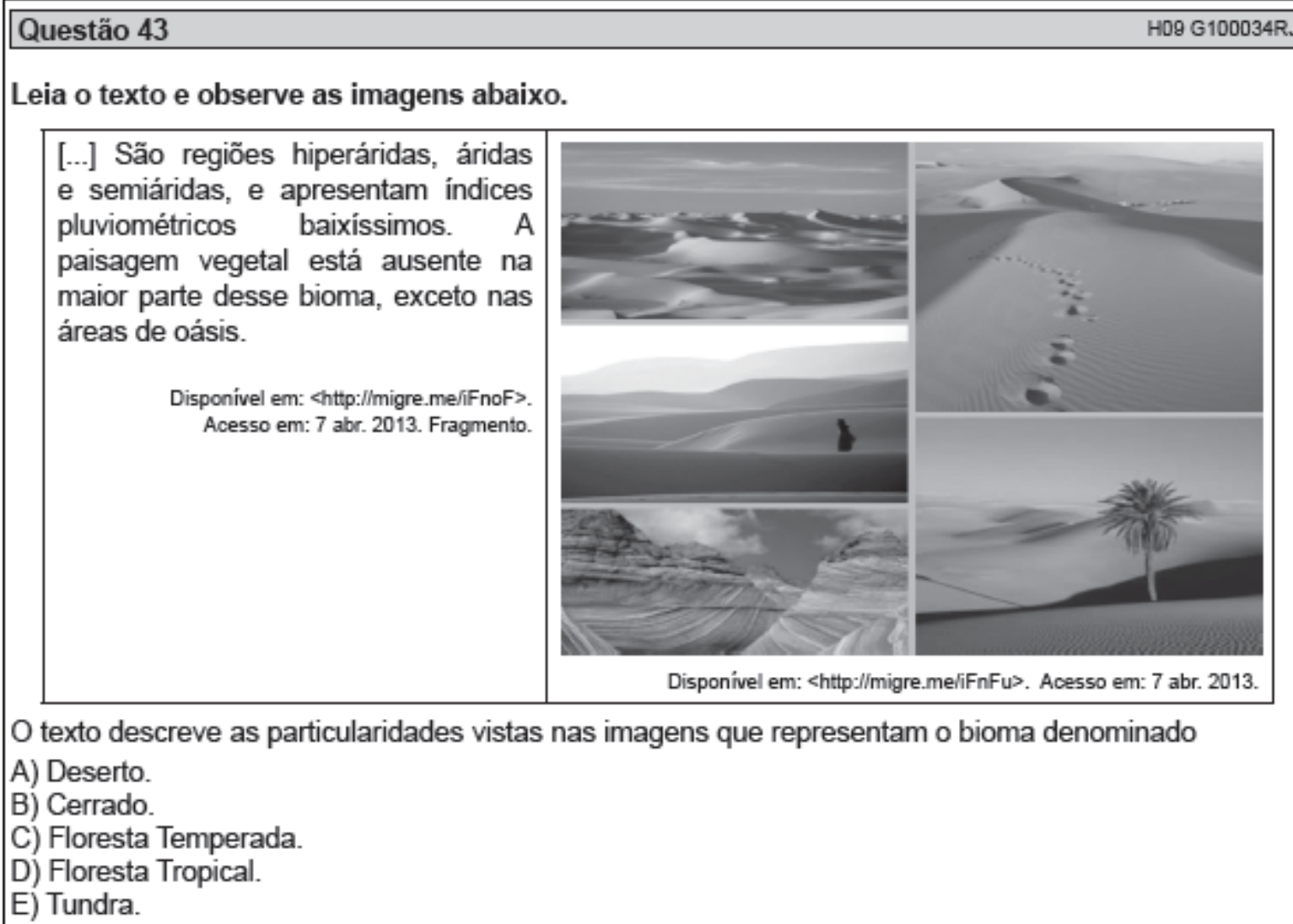

Fonte: 〈http://www.saerjinho.caedufjf.net/diagnostica/inicio.faces>. Acesso em: 01 ago. 2015.

Essa "facilidade", presente em praticamente todas as questões, leva a perceber que o maior objetivo da SEEDUC era que os alunos tivessem um grande número de acertos, mas não porque dominavam os conteúdos e desenvolveram uma capacidade crítica de pensar sobre os assuntos tratados. Os acertos ocorriam porque o que se perguntava era muito fácil, então só errava quem não lia a questão, o que aliás era muito comum entre os alunos, ou quem tinha muita dificuldade de leitura e trazia déficit grande de assuntos já muito tratados nos anos anteriores. Quanto maior o percentual de acertos, mais elevado seria o Iderjinho, índice fundamental para identificar se as avaliações do Saerjinho estavam atingindo os objetivos esperados.

Para Gadotti (1984 apud COPATTI, 2014, p. 172) "a avaliação é inerente e imprescindível durante todo processo educativo que se realize em um constante trabalho de ação-reflexão", mas sem essa ação-reflexão encerra-se na nota como o Saerjinho e não permite "problematizar o mundo em que vivemos para superar as contradições" (GADOTTI, 1984 apud COPATTI, 2014, p. 172). Para superar as contradições, ou ao menos tentar fazê-lo, é necessário que os alunos se sintam sujeitos capazes de promover 
essa ação em conjunto com toda a sociedade da qual fazem parte. É importante que a escola e as aulas de Geografia permitam fazer da ação educativa um grande instrumento de transformação social.

As provas do Saerjinho em nenhum momento provaram ser capazes de auxiliar nessa empreitada. A análise da questão 37 aplicada no ano de 2013 para as turmas de $2^{\circ}$ ano do Ensino Médio (figura 4) comprova essa afirmação. Nessa questão aparece a imagem de indústrias emitindo poluentes através de suas chaminés e pergunta-se qual o problema ambiental evidenciado. A própria legenda da imagem - "factory pollution" (poluição industrial) - oferece a resposta para a questão. Na verdade, em muitas dessas provas as legendas das imagens davam as respostas ao que estava sendo perguntado. Mais uma vez se exigi apenas uma rápida observação da imagem para responder de forma correta. Não há qualquer tipo de contextualização relativa a problemas ambientais ou exigência de um amplo conhecimento sobre o assunto para estabelecer relações e responder.

Figura 4 - Questão 37 da prova de Geografia do $1^{\circ}$ bimestre de 2013 - $2^{\circ}$ ano

Questão 37
Observe a imagem abaixo.
Disponivel em:<http///www.edupics.oom/coloring-page-factory-pollution-i7641.html . Acesso em: 7 mar. 2013.
O problema ambiental presente nessa imagem é
A) a ampliação do congestionamento, gerando a poluição sonora.
B) a contaminação hídrica, provocando a ocorrência das enchentes.
C) a presença das indústrias, ocasionando a poluição atmosférica.
D) o escoamento de poluentes, provocando a contaminação dos solos.
E) o uso excessivo de agrotóxicos, contaminando o lençol freático.

Fonte: 〈http://www.saerjinho.caedufjf.net/diagnostica/inicio.faces〉. Acesso em: 01 ago. 2015.

Segundo Libâneo (2004, apud COPATTI, 2014, p. 173) a avaliação da aprendizagem deve através da verificação e qualificação dos resultados "determinar a correspondência desses com os objetivos propostos e, daí, orientar a tomada de decisões em relação às atividades didáticas". Mas, em situações como as expostas nas questões do Saerjinho, inviabilizam-se as possibilidades de verificar e qualificar os resultados de uma prova que não foi construída pelo professor em conjunto com seus alunos e a partir delas orientar outras atividades didáticas que se desdobrariam em conhecimentos. A avaliação deve estar presente em todo o processo de ensino, sendo constante e não 
aparecer ao final de uma etapa sob a forma de prova elaborada externamente. Nas palavras de Carina Copatti (2014, pp. 173-174):

\begin{abstract}
A avaliação, quando utilizada para verificar e qualificar o processo de ensinoaprendizagem, torna-se uma ferramenta essencial no processo educativo, portanto, sua função não é "quantificar" o percentual que o aluno aprendeu. A avaliação engloba uma infinidade de critérios que precisam considerar também as atividades didáticas dos educadores e a aplicabilidade dessas na sala de aula. Furlan $(2007$, p. 39) considera que "tradicionalmente o que se observa é o processo de avaliação reduzir-se à verificação do conteúdo aprendido pelo aluno. Os professores avaliando através de instrumentos, de estilo tipicamente reprodutivo, cabendo ao aluno escutar as aulas, tomar nota e fazer prova". Ainda hoje, muitas instituições escolares e por que não dizer, muitos educadores, utilizam a avaliação enquanto medida, classificando os educandos, comparando-os e gerando uma espécie de "rótulo", distinguindo-os como "bons" ou "ruins".
\end{abstract}

O fato de as avaliações estarem sendo utilizadas muito mais para classificar do que para colaborar com a aprendizagem, fez com que se criasse na cabeça da maioria dos alunos a ideia de que o importante é obter uma nota para passar, mesmo que aquela nota não traduza o que foi aprendido. Tanto que grande parte dos alunos ainda concentram-se em decorar nomes e conceitos para apenas fazer uma prova, sem que sejam estabelecidas as devidas associações entre essas ideias fragmentadas. No entanto, este predomínio de aspectos quantitativos sobre os qualitativos não é o que está indicado na Lei de Diretrizes e Bases da Educação Nacional (LDB). No documento oficial que regulamenta as diretrizes para a educação nacional está descrito que "a avaliação do desempenho do aluno deve ser contínua e cumulativa, com prevalência dos aspectos qualitativos sobre os quantitativos e dos resultados ao longo do período sobre os de eventuais provas finais" (COPATTI, 2014, p. 74).

Na prática, no entanto, têm sido cada vez mais priorizadas as avaliações externas, que têm como principal foco a quantificação dos resultados que permitem a classificação de escolas e alunos. É deixada de lado a ideia de que "o aluno precisa ser avaliado durante todo o processo educativo, considerando diferentes aspectos que são essenciais na sua formação e não somente por meio de notas quantificáveis" (COPATTI, 2014, p. 174).

Outro exemplo desse foco nos resultados independente da qualidade do que se avalia é a questão 37 aplicada para os alunos do $3^{\circ}$ ano do Ensino Médio em 2014 (figura 5), essa apresenta um texto descritivo com lacunas e depois pergunta-se sobre o que está sendo falado. Como o texto deixa claro que trata-se de uma fonte de energia limpa e que encontra-se em estado gasoso fica bem fácil para o aluno entender do que se trata e assinalar a opção gás natural. 


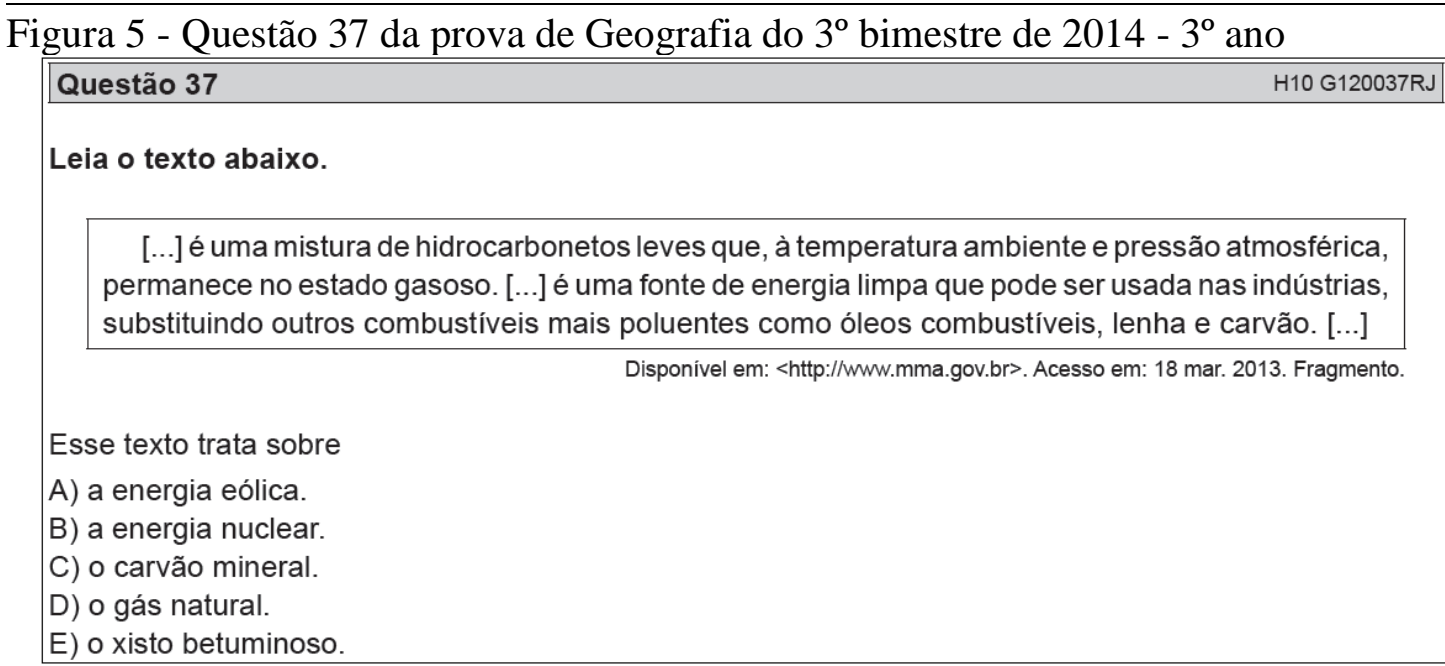

Fonte: 〈http://www.saerjinho.caedufjf.net/diagnostica/inicio.faces>. Acesso em: 01 ago. 2015.

Quando comparada as questões apresentadas para os outros anos de escolaridade a questão 37 (figura 5) apresenta um grau de complexidade um pouco maior, exigindo dos alunos mais conhecimento dos conteúdos abordados nas aulas, assim como maior capacidade de leitura e interpretação. Mas, ainda exige-se mais memorização do que entendimento do assunto. Não está sendo exigido capacidade de relacionar o assunto a experiências cotidianas dos alunos.

Não é o objetivo deste trabalho analisar cada uma das questões aplicadas nos quatro anos de escolaridade aqui destacados. Mas, apenas com esses rápidos exemplos é possível identificar as falhas presentes nas provas do Saerjinho, sobretudo no que se refere aos conteúdos e elaboração das questões.

Do ponto de vista dos conceitos geográficos, por exemplo, havia nessas provas o uso excessivo da divisão macrorregional feita pelo IBGE, sem que fossem ao menos citadas outras formas de regionalização. O mesmo ocorria com a regionalização do mundo em continentes que não deixava margens para analisar o mundo de outras maneiras. Nesses casos as provas reproduziam o que estava descrito na Matriz de Referência e no Currículo Mínimo - uma visão fragmentada de Geografia, que não permitia estabelecer relações entre os elementos estudados, tanto que nas provas as questões sequer tinham um encadeamento de ideias.

A SEEDUC tentava convencer pais, alunos e toda a sociedade de que essas provas estavam preparando os alunos para outras avaliações externas, no caso específico da prova de Geografia, a preparação serviria para o Enem. Contudo, com questões que estimulavam pouco a capacidade cognitiva dos alunos o que estava sendo feito era somente uma maquiagem para manter a improdutividade da escola, que continuava formando cidadãos acríticos para o mundo do trabalho.

Para Lígia Beatriz Goulart (2007 apud COPATTI, 2014, p. 174) a avaliação deve ter um caráter construtivo, "precisa ser pensada como possibilidade, de forma prospectiva, uma vez que desempenha um papel relevante na aprendizagem". A autora compara a ação avaliativa a uma bússola que indica caminhos, corrige rotas e retoma trajetórias.

Sem esse caráter construtivo o sistema avaliativo além de tornar-se um mero medidor de desempenho, também converte-se em instrumento de punição, pois os bons alunos são premiados com as melhores notas e os que são ruins recebem notas baixas, deixando evidente a separação e/ou distanciamento entre os dois grupos. Em avaliações como o Saerjinho esse caráter construtivo estava muito distante, o objetivo era 
basicamente a classificação, já que a própria escola estimulava a competitividade entre os alunos.

Para mudar essa situação Roberto Filizola (2009 apud COPATTI, 2014, p. 175) sublinha que:

\begin{abstract}
Em primeiro lugar, a avaliação não deve ficar restrita a provas e testes. Ao contrário, é necessário diversificar os instrumentos avaliativos tendo em vista ampliar as possibilidades de avanço dos alunos [...]. Em segundo lugar, o processo de avaliação da aprendizagem escolar não pode ser concebido como algo à parte do processo de ensino e até mesmo do projeto pedagógico. Nessa perspectiva, a avaliação deve possuir um caráter diagnóstico e, consequentemente, prestar-se para a verificação dos resultados planejados [...].
\end{abstract}

A avaliação do Saerjinho era considerada uma avaliação de caráter diagnóstico pela SEEDUC, mas como era feita por uma equipe fora da escola acabava ficando à parte do processo de ensino, não permitindo a construção de uma análise válida para a melhoria da qualidade do ensino. E mais, muitas escolas optavam por fazerem simulados constantes, como parte de suas avaliações, para treinar os alunos para as provas do Saerjinho, sendo assim, essa tornava-se quase que a única forma de avaliação realizada, não havendo diversificação do modo como se avaliava.

Segundo Furlan (2007 apud COPATTI, 2004, p.177) a avaliação não deve ser vista como um procedimento separado da aprendizagem. Para ele, ao avaliar, o professor observa o aluno e se observa enquanto professor. "Porém, isso não significa que a avaliação não deva ser formalizada. A escola precisa dar satisfação de suas ações, os alunos e os professores precisam da referência de alguns índices, que utilizados conscientemente, fornecem indicações de conhecimentos e apontam as intervenções necessárias".

Essa satisfação deve, no entanto, ser dada pela própria escola e não estar centrada em índices que apontam para resultados de toda a rede de ensino, exemplo dos resultados do Ideb que colocam o Ensino Médio do estado do Rio de Janeiro entre os quatro melhores do país. Nesse caso, constrói-se uma média entre todas as escolas da rede, mas isso não significa que uma dada escola é uma das quatro melhores do país. Cria-se a ilusão de que todo o sistema de ensino estadual está muito bem, sem pensar-se nas especificidades de uma escola, uma turma ou um aluno.

A estratégia do governo era convencer toda a população de que seu sistema de ensino ia muito bem, com grandes avanços educacionais, comprovados pela grande ascensão nas posições do Ideb. Ainda que as avaliações externas apresentassem resultados individualizados por escola e até mesmo por turmas e alunos, o que ficava exposto para a população eram os "avanços" gerais divulgados pela imprensa. Mas, no interior desse sistema muitas escolas apresentavam baixos índices e eram pressionadas pela SEEDUC para atingirem as metas pré-determinadas para cada bimestre e ano letivo. Para mascarar os resultados ruins a secretaria de educação também investia nas "melhores" escolas para que os bons resultados dessas compensassem os resultados ruins das demais. Prova disso era o sistema de bonificações.

A avaliação utilizada desse modo apenas classifica, mas não reconhece as potencialidades e limitações, tanto de alunos quanto de professores. Para Copatti (2014, p.177):

Avaliar não é somente o ato de atribuir uma nota ou estipular um conceito ao aluno, consiste em interpretar suas habilidades e estimular melhorias. Esse processo exige que se conheça muito da realidade deste e que se leve em consideração suas potencialidades. Avaliar o processo implica ir além dos 
conteúdos, é tecer a teia das relações sociais, refletir a realidade a partir de questões cotidianas, as quais estão além dos livros didáticos e dos muros da escola.

O modelo pautado na supervalorização das avaliações externas não permite conhecer a realidade e as potencialidades de cada aluno, assim como impede tratar das questões cotidianas que envolvem cada comunidade escolar. Essas avaliações tratam dos conteúdos estipulados pelos currículos oficiais que podem dar conta de questões mais gerais, distantes dos muros da escola, mas assim como afirma Carina Copatti (2014, p.177) não olham para a própria escola e suas especificidades.

A autora salienta ainda que "na disciplina de Geografia é de extrema importância realizar a avaliação formativa durante toda a ação pedagógica, deixando claro ao educando qual é o objetivo da avaliação que está sendo realizada, como essa avaliação ocorrerá durante as aulas e porque se faz necessária tal avaliação" (COPATTI, 2004, p.177). Para reforçar essas ideias a autora cita Filizola (2009, p. 55), que defende:

\begin{abstract}
A importância de restringir o uso de provas e incentivar a diversificação de instrumentos de avaliação na Geografia, para que o educando seja capaz de avançar com maior qualidade. Frente a isso, é importante instigar os educandos a serem parceiros e não competidores, buscando crescimento individual e coletivo e assim conquistando melhores resultados (FILIZOLA, 2009 apud COPATTI, p. 177).
\end{abstract}

As ações coletivas surtem mais efeitos, ainda mais quando se pensa na sociedade como um todo, pois essas são capazes de promover mudanças significativas. A escola não deve estimular o individualismo e a competitividade já tão presentes no mundo contemporâneo. Compete-se por notas, por trabalho, por uma vaga no estacionamento, ultrapassar no trânsito, idosos e deficientes físicos disputam para ver quem tem maior prioridade, etc. O papel da escola, em especial o das aulas de Geografia, não deve ser o de motivar tais ações. Ao contrário, deve-se banir do ambiente escolar o clima de competitividade, para que os alunos reproduzam na sociedade esse modo de pensar.

Não estimular o individualismo, contudo, não significa privar os alunos da autonomia, pois ser capaz de agir e pensar individualmente é essencial para a formação de cada indivíduo, até mesmo para torná-lo capaz de opinar e tomar decisões próprias em suas vivências coletivas.

Furlan (2007 apud COPATTI, 2014, p. 179) considera que:

Aprender implica esforço de elaboração própria, habilidade de argumentação com autonomia, saber pensar crítica e autocriticamente, produzir textos e materiais inteligentes, participação ativa envolvente. É sobre isso que o aluno deve ser avaliado e não pela quantidade de conteúdo que conseguiu reproduzir.

A quantidade de conteúdo que se compreende em dado momento não significa que foi criado no aluno pensamento crítico, ao contrário, muitas vezes um aluno pode dominar todo o conteúdo apenas para tirar boas notas nas provas e testes, apenas memorizando respostas prontas. Mas, quando indagado não sabe se posicionar e emitir opinião própria sobre o que foi estudado.

Não apenas nas aulas de Geografia, mas em todas as disciplinas, o que deve ser estimulado é a autonomia intelectual de cada aluno. Não basta que o aluno tire notas excelentes e seja aprovado, se o que ele fez foi apenas reproduzir o que está exposto em livros e na fala do professor. 


\begin{abstract}
É necessário que o aluno seja capaz de perceber as relações entre diferentes fenômenos que ocorrem nas mais diversas escalas e mais, que perceba o quanto ele e o seu entorno estão inseridos no mundo e fazem parte de uma totalidade.

Por isso, no que se refere à Geografia, segundo Copatti (2014, p. 179):

A avaliação precisa considerar os valores culturais, ou seja, não há como homogeneizar os educandos para que aprendam e constituam valores e sentimentos de maneira igualitária, pois cada indivíduo traz consigo suas vivências, suas histórias de vida e a cultura, herdada das experiências no contexto onde vive.
\end{abstract}

A cultura de cada grupo deve estar presente nas aulas, para que sejam percebidos os diferentes modos de vida e principalmente para que seja criado o respeito à diversidade. As aulas de Geografia devem motivar os alunos a terem pensamentos diversos, evidenciando que pessoas e grupos são diferentes e que por isso devem ser respeitados em suas particularidades. O momento da avaliação deve refletir isso, apontando para aspectos específicos das experiências cotidianas do grupo de alunos no qual está sendo inserida. Por fugir a essas ideias as avaliações externas recebem tantas críticas, já que priorizam a homogeneização em detrimento da diversidade inerente ao ambiente escolar e a sociedade como um todo.

Para auxiliar no processo de construção de conhecimentos mais adequados às necessidades dos alunos, segundo Copatti (2014, p. 185) as aulas de Geografia devem fazer uso de mapas, desenhos, imagens, tabelas, charges e ir além da visão e utilizar outros sentidos, como tato, olfato e audição.

Segundo Lana Cavalcanti (2008, p. 133 apud COPATTI, 2014, p. 188) para sair do que ela chama de formalismo didático é preciso que professores e alunos estejam realmente envolvidos no processo de ensino, o que requer dos professores a responsabilidade pela organização de atividades que levem em conta as necessidades individuais e sociais dos alunos. Para Carina Copatti (2014, p. 190) em conjunto essas ações contribuem para a "sensibilização dos educandos", momento que "deve ser parte do processo de avaliação, pois, medir a aprendizagem dos educandos de maneira quantitativa não é o bastante, precisamos desenvolver em nossos educandos inúmeras capacidades que vão além do simples ato de responder questões e decorar respostas".

No caso das políticas públicas educacionais aplicadas em escala nacional e na rede estadual de ensino do Rio de Janeiro, o sistema de avaliação ao invés de desenvolver essas capacidades, foi utilizado como instrumento para a precarização do ensino destinado a população de menor renda, utilizando-se o argumento de que todos teriam "igualdade de oportunidades", mas a metodologia e os instrumentos avaliativos garantiriam o processo discriminatório e seletivo. A avaliação passou a constituir-se em um instrumento para selecionar, classificar e rotular, fortalecendo o processo de exclusão dos alunos e garantindo a continuidade de uma estrutura econômica e social baseada em interesses políticos do sistema capitalista (LUCAS, 2000, p. 02).

\title{
CONSIDERAÇÕES FINAIS
}

Os projetos para a educação acompanhados da universalização da Educação Básica, em especial do Ensino Fundamental, finalmente ganharam grande impulso. Mas, esse processo trouxe como consequência a inserção precária de grande parte dos estudantes no contexto escolar, sobretudo no que se refere a qualidade do ensino. Qualidade essa que não pode ser vista apenas como um dado a ser mensurado, mas 
como a instrumentalização do indivíduo para melhor compreensão e capacidade de promover mudanças no mundo.

Os projetos que mobilizaram parte da sociedade civil tiveram seu protagonismo nos políticos e instituições financeiras, com destaque para a atuação dos bancos internacionais. Esses ajudaram a construir políticas educacionais que se caracterizaram pela construção de instrumentos capazes de mensurar o ensino, quantificando tanto o percentual de estudantes inseridos na escola, quanto construindo índices para medir a qualidade do que se ensina.

A ampliação de vagas e o maior financiamento da educação básica, que também se estendeu para a Educação Profissional e Ensino Superior na última década, sem nenhuma dúvida trouxe muitas possibilidades para a população, ainda que essas mudanças estivessem direcionadas aos interesses econômicos do país.

No estado do Rio de Janeiro, durante os governos de Sérgio Cabral, entre 2007 e 2014, com sequência dada por Luiz Fernando Pezão, as políticas voltadas para a construção de índices acentuaram-se.

As políticas de governo estiveram pautadas em cumprir as metas estabelecidas pelo Banco Mundial e outras instituições internacionais, para que toda a educação brasileira alcançasse o que se desejava. Assim, os estados que melhor se moldassem seriam mais beneficiados com recursos federais e financiamentos externos.

Como principais medidas o governo de Sérgio Cabral, após a sucessão de vários secretários de educação, criou as avaliações externas Saerj e Saerjinho e o Currículo Mínimo, para direcionar os conteúdos para essas avaliações.

As avaliações Saerj e Saerjinho, aplicadas anualmente e bimestralmente, respectivamente, serviriam para preparar os alunos da rede estadual para a realização da Prova Brasil, aplicada pelo governo federal a cada dois anos. Essas avaliações foram acompanhadas por medidas estratégicas como gestão escolar com perfil escolhido pelo governo, classificação das escolas em função dos resultados, maior fiscalização aplicada aos professores, em especial para que auxiliem no fluxo escolar, diminuindo as reprovações e abandonos, e na melhoria das notas nas avaliações externas.

O discurso criado pelos governos ao elaborar avaliações externas e currículos para atendê-las é o de que são esses métodos que vão produzir uma educação de qualidade. Por isso, convencem a sociedade e até mesmo os docentes, diretamente envolvidos no processo de ensino, de que essas são as melhores alternativas.

As estratégias criadas pelas secretarias de educação, em especial as que assumem como prioridade absoluta as avaliações externas como medidoras do que se considera ser a qualidade do ensino, tem provocado cada vez mais inércia nos professores. Por isso, a construção curricular não permite a participação efetiva da maioria e mesmo assim acaba servindo como parâmetro de ensino, embora grande parte dos docentes não concorde com o que está sendo proposto. O mesmo ocorre com o teor das avaliações externas, que como foi ilustrado com as questões de Geografia abordadas nas provas, não condiz com o que deveria ser cobrado para que os alunos construam um pensamento questionador. Mas, mesmo assim, essas provas, construídas fora da escola, tem ganhado cada vez mais peso, a ponto de muitos professores as apontarem como ideais para preparação dos alunos para outras avaliações, a exemplo do Enem.

O ensino de Geografia diante desse cenário deve ser capaz de construir reações, tanto por parte dos docentes quanto dos alunos para que esses não vejam em uma avaliação externa ou em um currículo fragmentado e distante de suas realidades cotidianas o único caminho possível para a construção do conhecimento. Nesse sentido, o papel da Geografia vai além da sala de aula, deve possibilitar a construção de um ensino que refute ideias de dominação e pouco questionadoras. A disciplina deve 
contribuir para mudanças no próprio sistema, na forma como têm sido impostas avaliações externas e uma proposta curricular desligada da realidade dos alunos e da possibilidade de formação de um pensamento crítico, que leve os alunos para além da informação.

\section{NOTA}

1- O texto aqui apresentado é parte da pesquisa de Mestrado realizada no Programa de Pós-Graduação em Geografia da Universidade do Estado do Rio de Janeiro (Uerj / Faculdade de Formação de Professores) entre os anos de 2013 e 2015.

\section{REFERÊNCIAS BIBLIOGRÁFICAS}

ARAUJO, T. S. O. de. Eu penso educação como um negócio: a meritocracia nas políticas educacionais do governo Sérgio Cabral Filho. Dissertação (Mestrado Profissionalizante em Educação Profissional em Saúde). Escola Politécnica de Saúde Joaquim Venâncio, Fundação Oswaldo Cruz , Rio de Janeiro, 2012.

COPATTI, Carina. Avaliação escolar em geografia: contribuições da educação estética nesse processo. Revista Olhares, São Paulo, v. 2, p. 168-193, 2014.

FRIGOTTO, Gaudêncio. A produtividade da escola improdutiva. 9. ed. São Paulo: Cortez, 2010. v. 1.263 p.

LUCAS, Rosa Elan Antória. A avaliação no processo ensino/aprendizagem da Geografia. Boletim Gaúcho de Geografia, Porto Alegre, jul. 2000.

MÉSZAROS, István. A educação para além do capital. 2. ed. São Paulo: Boitempo, 2008 .

PERRENOUD, Philippe. Sucesso na Escola: só o currículo, nada mais que o currículo! Cadernos de Pesquisa, Rio de Janeiro, n. 119, p. 7-26, jul. 2003.

SILVA, Isabelle F. O sistema nacional de avaliação: características, dispositivos legais e resultados. Estudos em Avaliação Educacional, São Paulo, v. 21, p. 427-448, 2010.

RIO DE JANEIRO (Estado). Secretaria de Educação. Currículo mínimo 2011, 2011a. Disponível em: <http://www.rj.gov.br/web/seeduc/exibeconteudo?article-id=374742>. Acesso em: $11 \mathrm{dez} .2013$.

Secretaria de Educação. Entenda para que servem o SERJ e o SERJINHO, 2011b. Disponível em: <http://www.rj.gov.br/web/seeduc/exibeconteudo?article$\mathrm{id}=616581>$. Acesso em: $11 \mathrm{dez} .2013$. 